\title{
Combined Activation of Guanylate Cyclase and Cyclic AMP in Lung Fibroblasts as a Novel Therapeutic Concept for Lung Fibrosis
}

\author{
Christopher Lambers $\mathbb{D D}^{1},{ }^{1}$ Panja M. Boehm, ${ }^{1}$ Yasemin Karabacak, ${ }^{2}$ Eslam Samaha, ${ }^{3}$ \\ Alberto Benazzo, ${ }^{1}$ Peter Jaksch, ${ }^{1}$ and Michael Roth $\mathbb{1}^{4}$ \\ ${ }^{1}$ Division of Thoracic Surgery, Department of Surgery, Medical University of Vienna, Austria \\ ${ }^{2}$ Center for Molecular Biology, University of Vienna, Austria \\ ${ }^{3}$ Division of Respiratory Medicine, Department of Internal Medicine II, Medical University of Vienna, Austria \\ ${ }^{4}$ Pulmonary Cell Research, Department of Biomedicine and Pneumology, Department of Internal Medicine, \\ University Hospital and University of Basel, Switzerland
}

Correspondence should be addressed to Christopher Lambers; christopher.lambers@meduniwien.ac.at

Received 15 August 2018; Revised 19 December 2018; Accepted 28 January 2019; Published 7 March 2019

Academic Editor: Coline van Moorsel

Copyright (C) 2019 Christopher Lambers et al. This is an open access article distributed under the Creative Commons Attribution License, which permits unrestricted use, distribution, and reproduction in any medium, provided the original work is properly cited.

Remodelling of the peripheral lung tissue and fibrotic foci are the main pathologies of idiopathic pulmonary fibrosis (IPF), a disease that is difficult to treat. TGF- $\beta$ activation of peripheral lung fibroblasts is indicated as the major cause of tissue remodelling in IPF and is resulting in fibroblast hyperplasia and deposition of extracellular matrix. Soluble guanylate cyclase (sGC) stimulators combined with cyclic AMP (cAMP) activators have been reported to reduce proliferation and matrix deposition in other conditions than IPF. Therefore, this drug combination may present a novel therapeutic concept for IPF. This study investigated the effect of BAY 41-2272 and forskolin on remodelling parameters in primary human lung fibroblasts. The study determined TGF- $\beta$ induced proliferation by direct cell counts after 3 days; and deposition of collagen type-I, type III, and fibronectin. BAY 41-2272 significantly reduced TGF- $\beta$ induced fibroblast proliferation, but did not reduce viability. This inhibitory effect was further supported by forskolin. Both BAY 41-2272 and forskolin alone reduced TGF- $\beta$ induced collagen and fibronectin de novo synthesis as well as deposition. This effect was significantly stronger when the two compounds were combined. Furthermore, the TGF- $\beta$ induced expression of fibrilar $\alpha$-smooth muscle actin was reduced by BAY 41-2272 and this effect was strengthened by forskolin. In addition, BAY 41-2272 and forskolin reduced TGF- $\beta$ induced $\beta$-catenin. All effects of BAY 41-2272 were concentration dependent. The findings suggest that BAY 41-2272 in combination with cAMP stimulation may present a novel therapeutic strategy to reduce tissue remodelling in IPF.

\section{Introduction}

Idiopathic pulmonary fibrosis (IPF) was considered a rare disease that was diagnosed mainly in patients older than 50 years of age $[1,2]$. However, a recent analysis indicated that its prevalence is increasing and equals today that of stomach, liver, testicular, and cervical cancers [3]. Worldwide, about 5 million people suffer from IPF with 12 per 100,000 newly diagnosed cases per year [4]. The cause of IPF is unknown, but smoking and viral infections, as well as the family history of IPF may be involved.
Diffuse tissue remodelling of the alveolar wall is the major pathology of IPF and seems to be resistant to available therapies $[1,5]$. Studies in human and animals implied that transforming growth factor- (TGF-) $\beta 1$ is a major cause of tissue remodelling in IPF and acts through tyrosine kinase receptors [6]. Currently, two drugs are approved for IPF therapy and both act by blocking tyrosine kinase receptors; however, their effect on tissue remodelling is drug specific $[7,8]$.

Isolated human IPF derived fibroblasts expressed markers, characterising the cells as myofibroblasts [9]. IPF 
fibroblasts are less flexible, express fibrilar collagen, and respond stronger to TGF- $\beta 1$ stimulation compared to nondiseased fibroblasts. Furthermore, IPF derived fibroblasts produced a disease specific extracellular matrix (ECM), which modified the behaviour of nondiseased fibroblasts. As a result, healthy fibroblasts seeded onto ECM produced by IPF fibroblasts, expressed $\alpha$-smooth muscle actin and phosphorylated Smad3 and STAT3. Furthermore, IPF derived ECM increased proliferation and migration of nondiseased fibroblasts [7]. These data suggest that the ECM produced by IPF fibroblasts must contain active TGF- $\beta$ and may explain the earlier described increase of TGF- $\beta$ and its receptors in IPF [10].

The ECM produced by IPF derived fibroblasts showed a disease specific modified expression of collagen type I, type III, and type V and fibronectin. The expression of all three ECM components was reduced by pirfenidone and nintedanib, however, in a drug-specific pattern [8]. In IPF, the stimulatory effect of the local composition of the ECM on fibroblast proliferation can either result from the mitogenic effect of collagen type I as shown in nondiseased human lung fibroblasts [11] or from the direct proproliferative effect of TGF- $\beta 1$ released from alveolar epithelial cells [12]. Furthermore, IPF derived fibroblasts were less sensitive to collagen type I induced cell death, which was explained by the lack of Akt/mTOR signalling [13]. Together, these studies suggested that IPF may result from faulty signalling of resident fibroblasts responding to the modified ECM surrounding them [14]. The two drugs available for IPF therapy, pirfenidone and nintedanib, improve lung function [15], but have different effects on remodelling parameters of IPF patients, indicating that additional therapeutic options should be investigated.

In animal models of other types of fibrosis, soluble guanylate cyclase (sGC) stimulators reduced fibrotic events. The de novo synthesis of collagen type I was reduced by sGC due to the inhibition of TGF- $\beta 1$ induced Erk1/2 signalling in human lung fibroblasts $[16,17]$. In pulmonary hypertension, the sGC stimulator, BAY 41-8543, reduced vessel wall fibrosis $[6,18]$. BAY 41-2272 reduced vascular remodelling and right heart ventricular hypertrophy, which resulted from profibrotic remodelling [19]. These studies suggested that sGC are a new class of drugs that could be used in IPF therapy.

The role of cyclic-AMP (cAMP) in the pathogenesis of IPF had been investigated in a few studies and showed its interaction with TGF- $\beta$ signalling $[20,21]$. In IPF derived fibroblasts, cAMP activation reduced proliferation and ECM deposition [22]. In bronchial epithelial cells of COPD patients, the activation of cAMP by other classes of drugs also prevented TGF- $\beta$ induced remodelling and epithelial-mesenchymal transition [23].

In this study, the effect of BAY 41-2272 alone and in combination with cAMP activator (forskolin) on fibroblast proliferation and deposition of ECM components was investigated.

\section{Methods}

Nondiseased human lung fibroblasts (CC-2512) were obtained from Lonza, Switzerland, and were grown using standard protocols. Experiments were performed in 70\%$80 \%$ confluent cell cultures between passages five to eight. Fibroblasts were grown in PRMI-1640 supplemented with $10 \%$ fetal calf serum, $20 \mathrm{mM}$ HEPES, $8 \mathrm{mM}$ L-glutamine (GlutaMAX), and $1 \times$ nonessential amino acid mixture (all: Gibco/BRL, Thermo Fisher Scientific, Switzerland). Cells were characterised by their long stretched spindle phenotype which stained positive for fibronectin and inducible staining for $\alpha$-smooth muscle actin ( $\alpha$-SMA).

2.1. Cell Proliferation and Cell Viability. Cell proliferation and cell viability were determined by direct cell count using Nexcelom Cellometer T4 $\odot$ (Nexcelom Bioscience, Lawrence, Massachussetts, USA) and Trypan blue staining after 24 and 72 hours of incubation according to the manufacturer's protocol [24].

2.2. Quantitative Real-Time PCR. Total mRNA was isolated using the TRIZOL standard protocol and directly transcribed into cDNA using a reverse transcriptase kit (Advantage RT-for-PCR Kit, Clontech, BD Biosience, Palo Alto, USA) according to the manufacturer's instructions. Real-Time PCR was performed using a LightCycler480 (Roche Diagnostics, Mannheim, Germany) to determine mRNA of the following genes: collagen type I and type III, fibronectin, $\alpha$-SMA, and $\beta$-catenin (TaqMan gene expression assays), Applied Biosystems (ABI, CA, USA). PCR conditions were 45 cycles with $95^{\circ} \mathrm{C}$ for $10 \mathrm{sec}, 65^{\circ} \mathrm{C}$ for $30 \mathrm{sec}$, and $72^{\circ} \mathrm{C}$ for $5 \mathrm{sec}$. Humanl8s or Actin TaqMan Predeveloped Assay (ABI, UK) was used as control. The target gene was normalized against the reference gene (18s/ACTIN mRNA) and data was expressed as relative increase or decrease from baseline values. Relative mRNA expression was determined using the $\Delta \mathrm{CT}$ method. $\Delta \mathrm{CT}$ indicates the difference between the amplification cycles of the target and the housekeeping gene [24].

2.3. Protein Expression and Extracellular Matrix Deposition. Deposition of collagen types I and III and of fibronectin was determined using a cell based ELISA as described earlier [24]. All antibodies were obtained from Santa Cruz Bio Technology (Santa Cruz, USA; COL1A1 SC-8784, COL3A1 sc271249, fibronectin SC-6952) and diluted 1:5'000 in blocking buffer. Secondary antibodies (Santa Cruz Bio Technology) were species specific and diluted 1:1'000 in blocking buffer; incubation was 1 hour (room temperature). After $3 \mathrm{x}$ washes with PBS optical densitometry was performed by ELISA reader (Thermofisher Scientific).

Structure and protein levels of $\alpha$-SMA and $\beta$-catenin were determined by immunocytochemistry in cells which were grown on cover slips after 24-hour treatment. Cells were washed once with PBS, fixed in $4 \%$ formalin ( $2 \times 5$ minutes), followed by $1 \mathrm{x}$ wash with PBS, blocking in PBS, $0.01 \%$ Tween $20,2 \%$ bovine serum albumin (30 minutes), before being incubated overnight $\left(4^{\circ} \mathrm{C}\right)$ with the first antibody for $\alpha$-SMA (Santa Cruz Biotech, sc-53015) or for $\beta$-catenin (Santa Cruz 


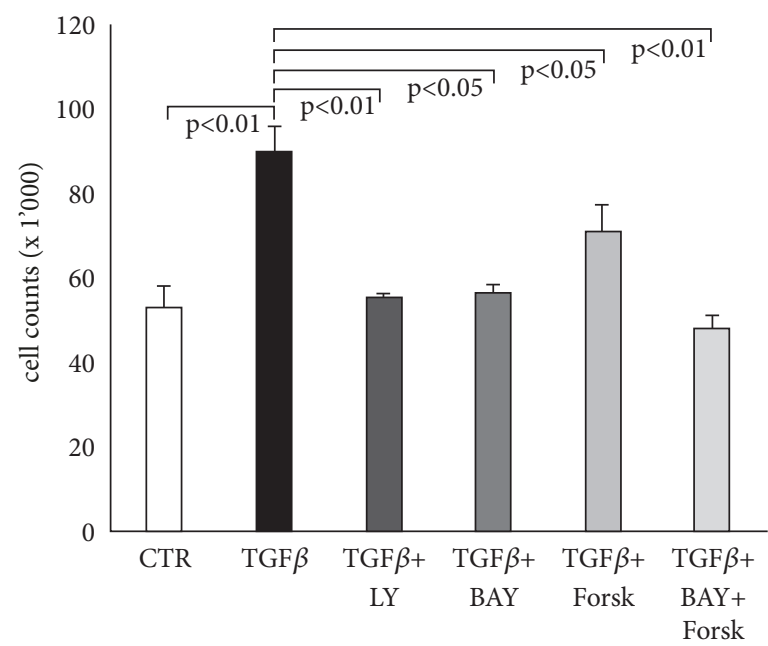

FIGURE 1: sGC and cAMP activation reduce TGF- $\beta 1$ stimulated fibroblast proliferation. Fibroblasts were preincubated for 30 minutes with either BAY 41-2272 $\left(10^{-6} \mathrm{M}\right)$, LY2157299 $\left(10^{-6} \mathrm{M}\right)$ or forskolin $\left(10^{-6} \mathrm{M}\right)$ before being stimulated with TGF- $\beta 1$ (10ng/ml) for 3 days. Cell counts were performed in triplicate and bars represent the mean \pm SEM. $P$ values were calculated by paired Student's t-test.

Biotec, sc-59737). After 3x washes with PBS, slides were incubated with a FITC labelled antibody (30 minutes, room temperature), nuclei were stained by DAPI, and pictures were obtained after $3 \mathrm{x}$ washes in PBS by EVOS FL cell imaging system (Thermofisher Scientific, Switzerland).

2.4. Statistical Analysis. Data are presented as mean \pm standard deviation (SD). The null hypothesis showed no difference between treated and untreated cells. Protein expression and mRNA transcription were compared by Student's ttest (two-tailed, paired). Results were considered statistically significant with $\mathrm{p}$ value $<0.05$.

\section{Results}

3.1. Combined sGC and cAMP Activation Prevented TGF$\beta 1$ Induced Cell Proliferation. Stimulation of human lung fibroblasts with TGF- $\beta 1$ significantly increased fibroblast proliferation up to 1.7 -fold ( $\mathrm{p}<0.01$ ) within 72 hours, as compared to unstimulated cells (Figure 1). The mitogenic effect of TGF$\beta 1$ was completely reduced by the TGF- $\beta 1$ inhibitor Galunisertib (LY2157299) ( $\mathrm{p}<0.01$, Figure 1). A similar inhibitory effect on TGF- $\beta 1$ induced proliferation was observed when fibroblasts were preincubated with BAY 41-2272 ( $\mathrm{p}<0.05$; Figure 1). Activation of cAMP by forskolin also significantly reduced TGF- $\beta 1$-induced fibroblast proliferation; however, with a lower efficacy compared to BAY 41-2272 (Figure 1). Combining BAY 41-2272 with forskolin completely prevented proliferation (Figure 1). Cell viability was determined by Trypan blue exclusion staining and showed no reduced viability under any treatment (data not shown).

The antiproliferative effect of BAY 41-2272 and forskolin was further investigated in order to determine a possible synergistic effect of the drugs when combined. As shown in Figure 2(a), BAY 41-2272 reduced proliferation in a concentration-dependent manner and the inhibition became significant at concentrations $>10^{-10} \mathrm{M}$ (Figure 2(a)).
Forskolin alone reduced proliferation and the effect became significant at concentrations $>10^{-8} \mathrm{M}$; however, the effect was not clearly concentration dependent (Figure 2(b)). The maximal inhibitory effect was $47.8 \%$, which was achieved at $10^{-6} \mathrm{M}$. When cells were treated with BAY $41-2272$ at $10^{-9} \mathrm{M}$ combined with forskolin with increasing concentration from $10^{-10}$ to $10^{-6} \mathrm{M}$, the antiproliferative effect was stronger than each drug alone (Figure 2(c)). Vice versa, when cells were treated with forskolin at $10^{-9} \mathrm{M}$ combined with BAY 41-2272 with increasing concentration from $10^{-12}$ to $10^{-8} \mathrm{M}$, the antiproliferative effect was increasing in a concentration dependent manner and was stronger compared to each drug alone (Figure 2(d)). None of the antiproliferative drugs described above significantly decreased cell viability as determined by Trypan blue staining (data not shown).

\section{2. $s G C$ and cAMP Activation Inhibited TGF- $\beta 1$ Induced} Synthesis and Deposition of Collagens. TGF- $\beta 1$ significantly increased the mRNA encoding for collagen type I as shown in Figure 3(a). When preincubated with the TGF- $\beta 1$ inhibitor (LY), the stimulatory effect was completely neutralised. In the presence of BAY 41-2272, the synthesis of collagen type I mRNA was reduced by $52 \%$ and in the presence of forskolin by $98 \%$. When BAY 41-2272 was combined with forskolin, the collagen type I mRNA level was reduced by $80 \%$, compared to TGF- $\beta 1$ alone (Figure 3(a)).

On the protein level, TGF- $\beta 1$ dose dependently increased the deposition of collagen type I. This effect became significant at concentration $>0.5 \mathrm{ng} / \mathrm{ml}$ (Figure $3(\mathrm{~b})$ ). When fibroblasts were preincubated with increasing concentrations with BAY 41-2272, the deposition of collagen type I was significantly reduced at concentration $>1 \mu \mathrm{M}$ (Figure $3(\mathrm{c})$ ). Adding forskolin to BAY 41-2272 further increased the reducing effect on the TGF- $\beta 1$ stimulated collagen type I deposition (Figure 3(c)). However, the additional effect of forskolin did not become significant compared to BAY 412272 alone. 


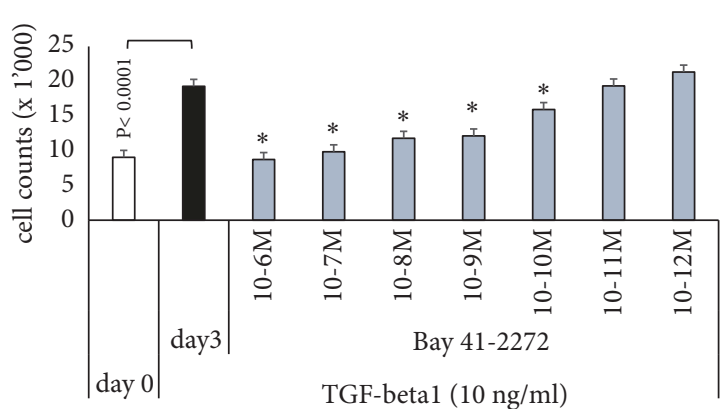

(a)

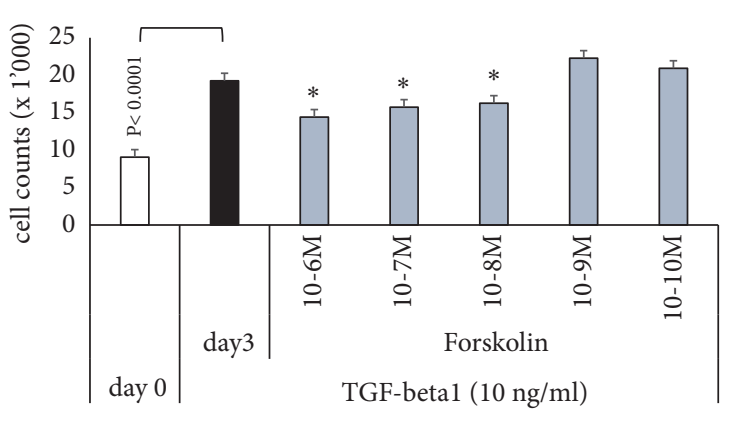

(c)

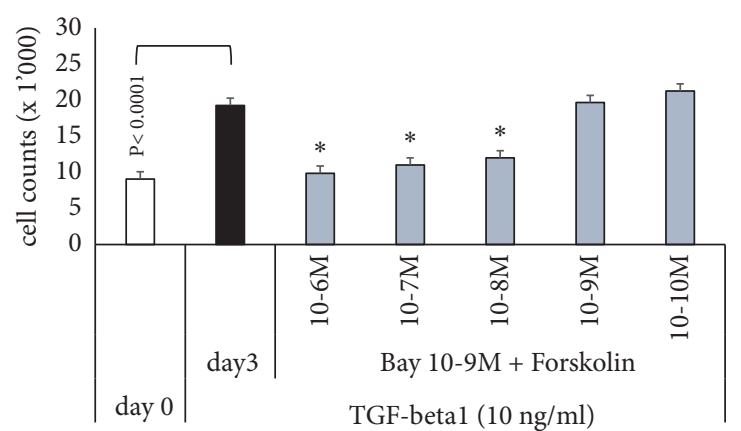

(b)

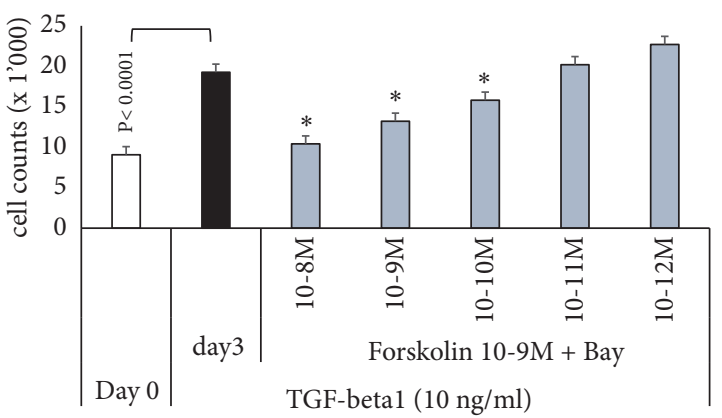

(d)

FIGURE 2: Concentration dependent antiproliferative action of sGC and cAMP activators on TGF- $\beta 1$ induced fibroblast proliferation. (a) Concentration dependent antiproliferative effect of BAY 41-2272 over 3 days; (b) Concentration dependent anti-proliferative effect of forskolin. (c) Supportive effect of forskolin $\left(10^{-10}-10^{-6} \mathrm{M}\right)$ on BAY 41-2272 $\left(10^{-9} \mathrm{M}\right)$ inhibition of fibroblast proliferation. (d) Supportive effect of BAY 41$2272\left(10^{-12}-10^{-8} \mathrm{M}\right)$ on forskolin $\left(10^{-9} \mathrm{M}\right)$ inhibited proliferation. Bars represent mean \pm SEM of triplicate experiments. * indicates statistically significant difference $(\mathrm{P}<0.05)$ for comparison of TGF- $\beta 1$ stimulation compared to drug effects.

Depicted in Figure 4(a), the transcription of collagen type III mRNA was significantly increased by TGF- $\beta 1$. Inhibition of TGF- $\beta 1$ (LY) reduced collagen type III mRNA to baseline level and in the presence of BAY 41-27272, a similar effect was achieved (Figure 4(a)). Preincubation with forskolin also reduced the effect of TGF- $\beta 1$ on collagen type III mRNA expression by $58 \%$ (Figure $4(\mathrm{a})$ ). Fibroblasts pretreated with the combination of BAY 41-2272 and forskolin did not respond to TGF- $\beta 1$ stimulation, and mRNA expression for collagen type III was at baseline level (Figure 4(a)).

On the protein level, TGF- $\beta 1$ increased collagen type III deposition in a concentration dependent manner achieving significance at concentrations $>1 \mathrm{ng} / \mathrm{ml}$ (Figure 4(b)). Preincubation with BAY 41-2272 reduced TGF- $\beta 1$ induced collagen type III deposition in a concentration dependent manner, which achieved significance only at $10 \mu \mathrm{M}$ (Figure $4(\mathrm{c})$ ). The combination of BAY 41-2272 and forskolin was more effective as shown in Figure 4(c).

TGF- $\beta 1$ significantly upregulated the expression of fibronectin mRNA in human lung fibroblasts (Figure 5(a)). Inhibiting TGF- $\beta 1$ by LY2157299 reduced fibronectin mRNA by $82 \%$, but did not completely block the effect of TGF- $\beta 1$ (Figure 5(a)). BAY 41-2272 reduced fibronectin mRNA in fibroblasts stimulated with TGF- $\beta 1$ by only $33 \%$ (Figure 5(a)). Forskolin had no significant reducing effect on TGF- $\beta 1$ induced fibronectin mRNA expression and when combined with BAY 41-2272, this effect was even lower (Figure 5(a)).
TGF- $\beta 1$ increased fibronectin deposition in a concentration dependent manner and the effect was significant at concentrations $>0.1 \mathrm{ng} / \mathrm{ml}$ (Figure 5(b)). In the presence of BAY 41-2272, the TGF- $\beta 1$ induced deposition of fibronectin was only marginally reduced (Figure 5(c)). However, when combined with forskolin, the deposition of fibronectin was reduced and achieved significance at the highest concentrations of both drugs (Figure 5(c)).

3.3. BAY 41-2272 Reversed TGF- $\beta 1$ Induced $\alpha$-SMA and $\beta$-Catenin Expression and Structure. TGF- $\beta 1$ induced the expression of mRNA encoding for $\alpha$-SMA, and this effect was reduced by $35 \%$ in the presence of the TGF- $\beta 1$ inhibitor (LY) as shown in Figure 6(a). BAY 41-2272 reduced the mRNA level of $\alpha$-SMA in TGF- $\beta 1$ stimulated fibroblasts to baseline level (Figure 6(a)). Forskolin alone reduced $\alpha$-SMA mRNA expression by $80 \%$, and when combined with BAY $41-2272$, it completely prevented TGF- $\beta 1$ induced $\alpha$-SMA mRNA expression (Figure 6(a)).

Unstimulated fibroblasts expressed a low level of $\alpha$-SMA in the cytosol as shown in Figure 6(b). TGF- $\beta 1$ significantly increased the expression of $\alpha$-SMA and changed the confirmation of the protein into contractile fibrils (Figure 6(b)). When preincubated for 30 minutes with BAY 41-2272, the effect of TGF- $\beta 1$ on the expression and arrangement of $\alpha$-SMA was prevented (Figure 6(b)). Forskolin had a less 


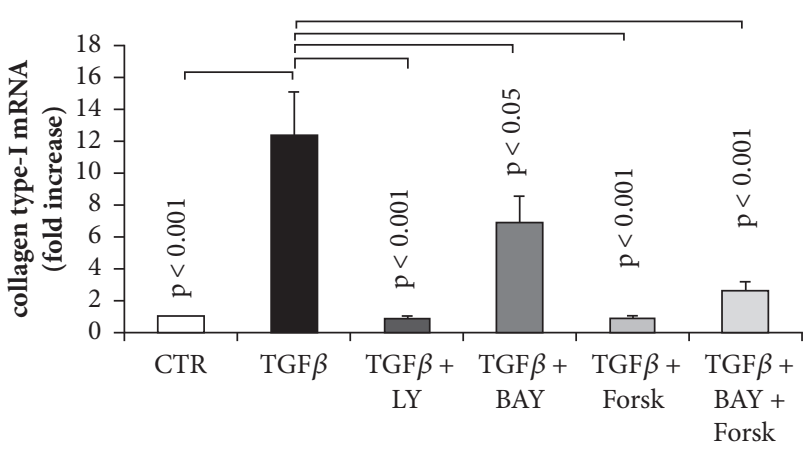

(a)

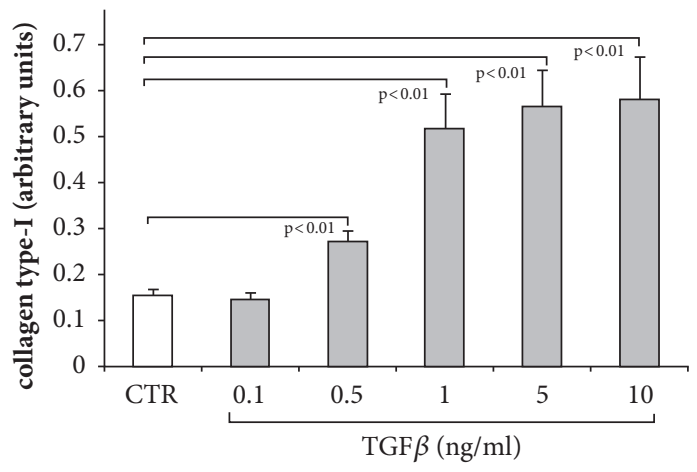

(b)

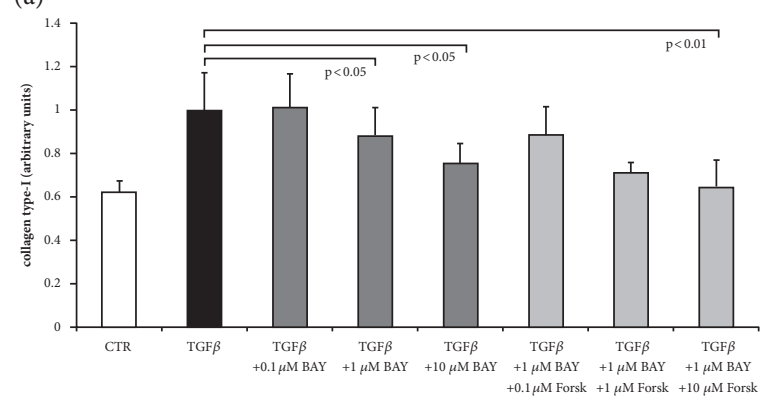

(c)

FIGURE 3: Concentration and time dependent effect of TGF- $\beta 1$ treatment on collagen type-I de novo synthesis and deposition in the absence and presence of sGC and cAMP activators. (a) Inhibition of TGF- $\beta 1$ by LY2157299 $\left(10^{-6} \mathrm{M}\right)$, or preincubation (30 min) with BAY $41-2272$ $\left(10^{-6} \mathrm{M}\right)$ or forskolin $\left(10^{-6} \mathrm{M}\right)$ significantly reduced transcription of the collagen type-I gene at 24 hours. (b) Concentration dependent induction of collagen type I deposition by TGF- $\beta 1$. (c) Inhibition of collagen type I deposition by increasing concentration of BAY $41-2272$ and forskolin in TGF- $\beta 1$ stimulated fibroblasts at 24 hours. Bars represent mean \pm SEM of triplicate experiments.

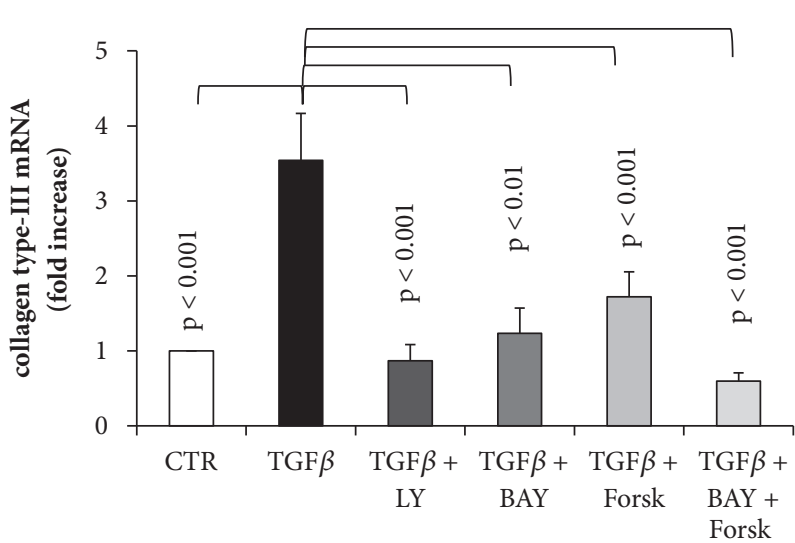

(a)

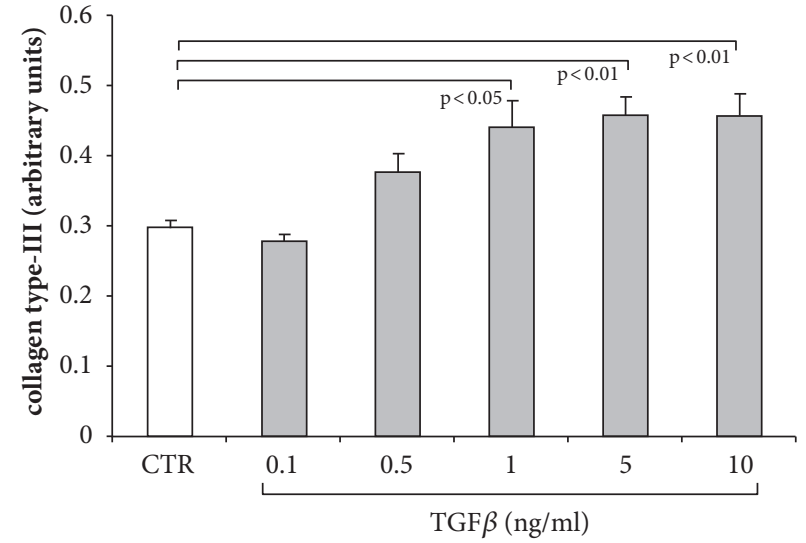

(b)

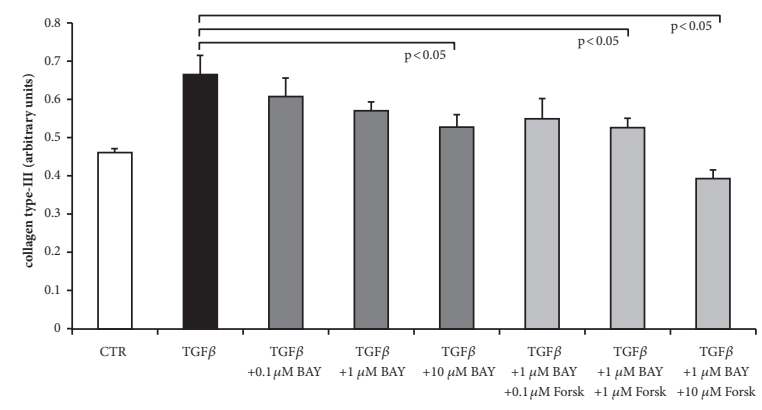

(c)

FIgURE 4: Concentration and time dependent effect of TGF- $\beta 1$ treatment on collagen type III de novo synthesis and deposition in the absence and presence of sGC and cAMP activators. (a) Inhibition of TGF- $\beta 1$ by LY2157299 $\left(10^{-6} \mathrm{M}\right)$, or preincubation (30 min) with BAY $41-2272$ $\left(10^{-6} \mathrm{M}\right)$ or forskolin $\left(10^{-6} \mathrm{M}\right)$ significantly reduced transcription of the collagen type III gene at 24 hours. (b) Concentration dependent induction of collagen type III deposition by TGF- $\beta 1$. (c) Inhibition of collagen type III deposition by increasing concentration of BAY 41-2272 and forskolin in TGF- $\beta 1$ stimulated fibroblasts at 24 hours. Bars represent mean \pm SEM of triplicate experiments. 


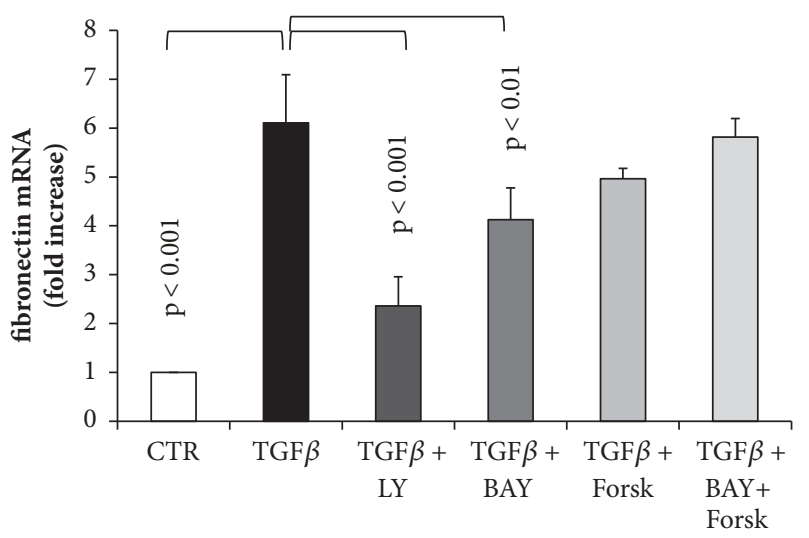

(a)

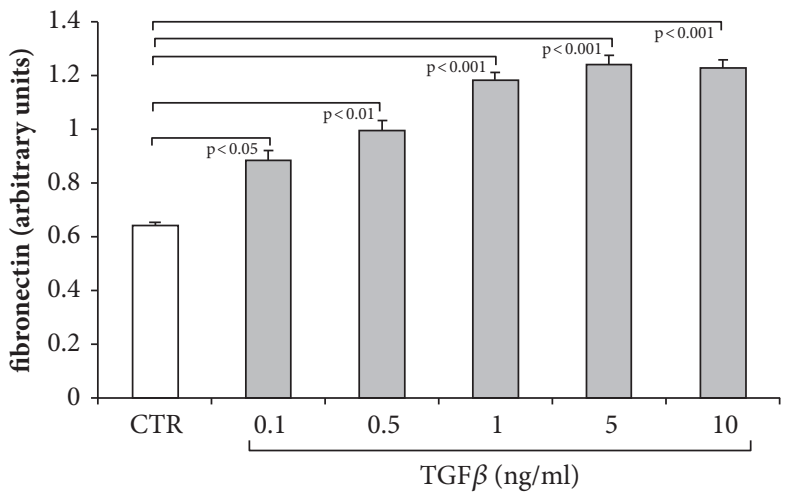

(b)

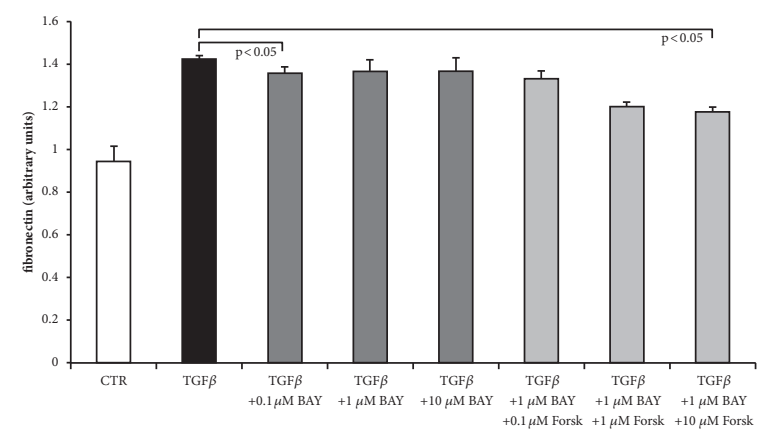

(c)

FIGURE 5: Concentration and time dependent effect of TGF- $\beta 1$ treatment on fibronectin de novo synthesis and deposition in the absence and presence of sGC and cAMP activators. (a) Inhibition of TGF- $\beta 1$ by LY2157299 $\left(10^{-6} \mathrm{M}\right)$, or preincubation (30 min) with BAY $41-2272$ $\left(10^{-6} \mathrm{M}\right)$ or forskolin $\left(10^{-6} \mathrm{M}\right)$ significantly reduced transcription of the fibronectin gene at 24 hours. (b) Concentration dependent induction of fibronectin deposition by TGF- $\beta 1$. (c) Inhibition of fibronectin deposition by increasing concentration of BAY 41-2272 and forskolin in TGF- $\beta 1$ stimulated fibroblasts at 24 hours. Bars represent mean \pm SEM of triplicate experiments.

prominent reducing effect on both expression and arrangement of $\alpha$-SMA (Figure 6(b)).

The expression of $\beta$-catenin mRNA was significantly increased by TGF- $\beta 1$ within 24 hours, and this effect was nearly completely prevented in the presence of TGF- $\beta 1$ inhibitor (Figure 7(a)). Similarly the preincubation of fibroblasts with BAY 41-2272, or forskolin, or the combination of both was effective; the mRNA level of $\beta$-catenin in TGF- $\beta 1$ stimulated fibroblasts was reduced to baseline level by each of the treatments (Figure 7(a)).

As shown by immunochemistry, $\beta$-catenin was expressed at a higher level in the cytosol of fibroblasts stimulated with TGF- $\beta 1$, compared to unstimulated fibroblasts (Figure 7(b)). The expression of $\beta$-catenin was significantly reduced in fibroblasts that were preincubated either BAY 41-2272 or forskolin.

\section{Discussion}

IPF is characterised by the accumulation of fibroblasts and increased ECM deposition, which resembles features of scar formation, and were assigned as fibrotic foci [25]. Both events are assumed to result from increased levels of TGF- $\beta 1$, which were described in fibrotic tissues of IPF patients [26]. The experiments described above confirmed the antifibrotic effect of cAMP activation by forskolin, as well as a novel antiproliferative effect or BAY 41-2272, which is dependent on the activation of sGC. The combination of both classes of drugs showed an improved effect to each drug alone; however, the effect was additive rather than synergistic. In regard to ECM deposition, the presented data indicates that neither of the drugs has a general inhibitory effect and it is necessary to assess the drug effect on each component of the ECM. Furthermore, the presented data suggest that sGC combined with cAMP activation reduces the development of myofibroblasts. The above data indicate that sGC such as BAY 41-2272 may help to reduce the progression of fibrosis.

In IPF, increased proliferation of local resident lung fibroblasts has been suggested to result in fibrotic foci formation [27]. In addition, epithelial to mesenchymal transition (EMT) was reported to cause the same pathologies [9, 28]. Both proliferation and EMT have been linked to the increased activity of TGF- $\beta 1$ in IPF $[29,30]$ and involved Wnt and $\beta$-catenin signalling [31]. In human embryonic pulmonary fibroblasts, it was reported that Wnt and $\beta$ catenin activation led to pathological features resembling IPF [32]. In an animal model, Wnt signalling was essential for TGF- $\beta 1$ induced myofibroblasts generation [33]. Inhibition of $\beta$-catenin reduced EMT in an immortalised cell line, A549, which was used as a model for pulmonary fibrosis 


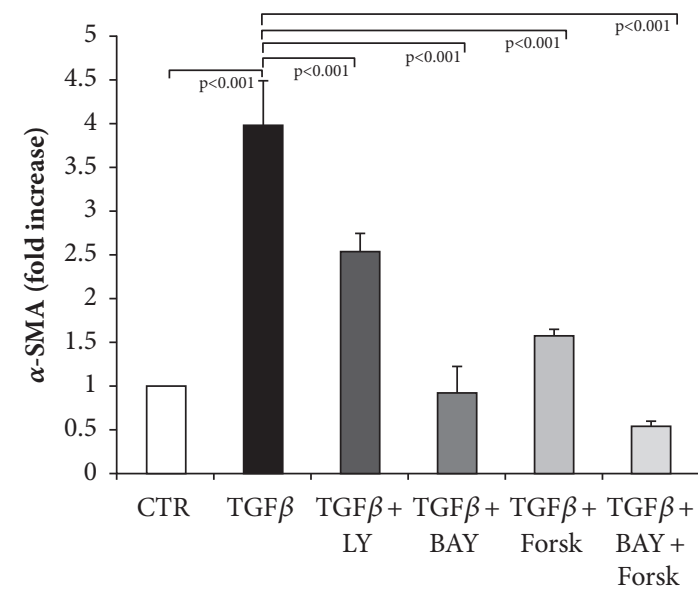

(a)

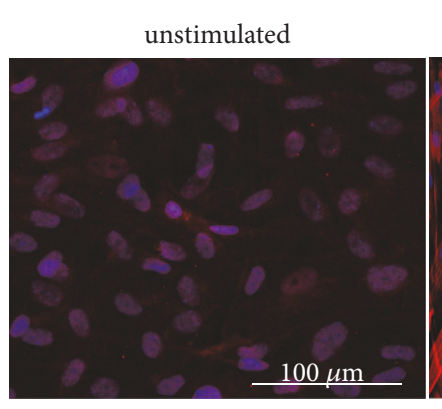

TGF- $\beta 1$ ( 5 ng/ml/24 hrs)

$$
+ \text { BAY 41-2272 (1 } \mu \mathrm{M})
$$

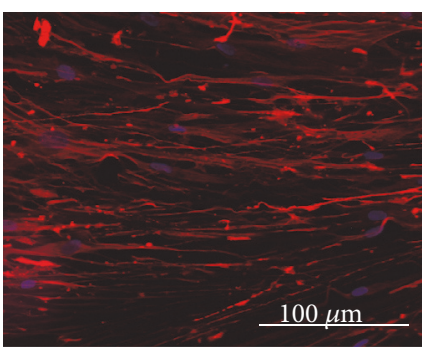

(b)
TGF- $\beta 1$ ( 5 ng/ml/24 hrs)

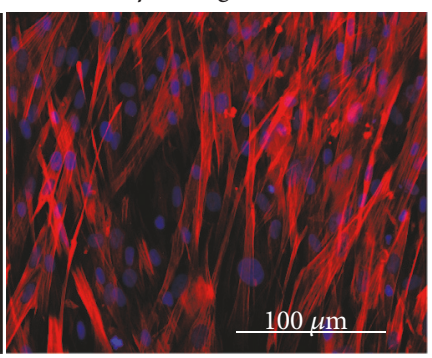

TGF- $\beta 1$ ( $5 \mathrm{ng} / \mathrm{ml} / 24 \mathrm{hrs})$

+ forskolin $(1 \mu \mathrm{M})$

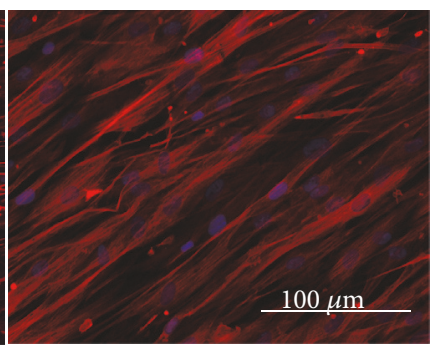

b)

FIGURE 6: Blockade of myofibroblasts differentiation by sGC and cAMP activation. (a) Transcription of $\alpha$-SMA was inhibited by LY2157299, BAY 41-2272 and forskolin (all at $10^{-6} \mathrm{M}$ ) in TGF- $\beta 1$ stimulated fibroblasts. Bars represent mean \pm SEM of triplicate experiments. (b) Representative immunochemical staining for $\alpha$-SMA in unstimulated cells (left upper panel), TGF- $\beta 1$ ( $5 \mathrm{ng} / \mathrm{ml}$ ) stimulated fibroblasts (right upper panel), and cells preincubated $(30 \mathrm{~min})$ with increasing concentrations of either BAY $41-2272$ or forskolin followed by TGF- $\beta 1$ stimulation $(5 \mathrm{ng} / \mathrm{ml})$. Similar results were obtained in three additional experiments.

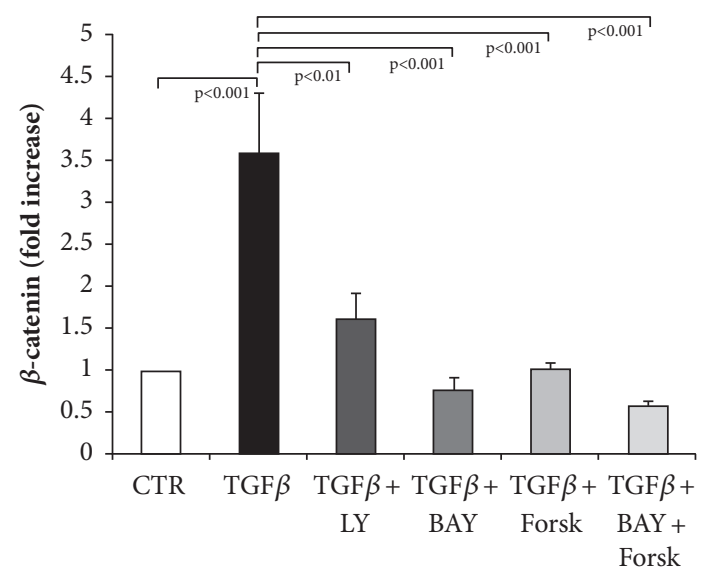

(a)

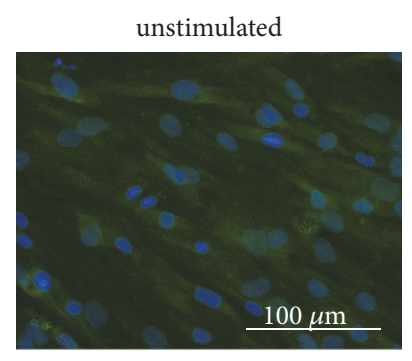

TGF- $\beta 1$ ( 5 ng/ml/24 hrs) + BAY 41-2272 (1 $\mu \mathrm{M})$

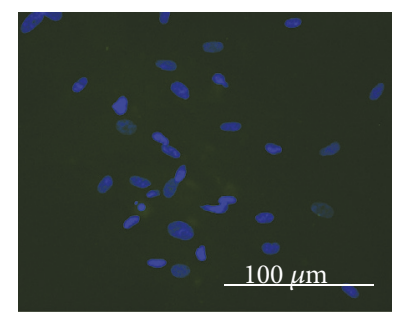

TGF- $\beta 1$ ( $5 \mathrm{ng} / \mathrm{ml} / 24 \mathrm{hrs}$

+ forskolin $(1 \mu \mathrm{M})$

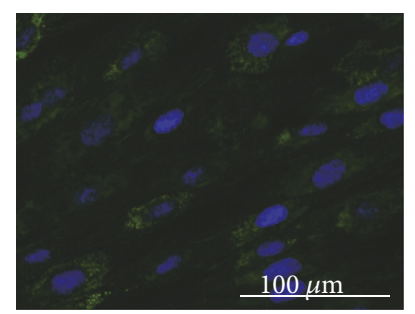

(b)

FIGURE 7: Blockade of $\beta$-catenin expression in fibroblasts by sGC and cAMP activation. (a) Transcription of $\beta$-catenin was inhibited by LY2157299, BAY 41-2272, and forskolin (all at $10^{-6} \mathrm{M}$ ) in TGF- $\beta 1$ stimulated fibroblasts. Bars represent mean \pm SEM of triplicate experiments. (b) Representative immunochemical staining for $\beta$-catenin in unstimulated cells (left upper panel), TGF- $\beta 1$ ( $5 \mathrm{ng} / \mathrm{ml}$ ) stimulated fibroblasts (right upper panel), and cells preincubated (30 min) with increasing concentrations of either BAY 41-2272 or forskolin followed by TGF- $\beta 1$ stimulation $(5 \mathrm{ng} / \mathrm{ml})$. Similar results were obtained in three additional experiments. 
[34]. Furthermore, inhibition of Wnt signalling supported the engraftment of mesenchymal stem cells into damaged lung tissues and therefore improved tissue repair [35]. The observation that $\mathrm{sGC}$ and cAMP activity downregulated TGF- $\beta 1$ induced $\beta$-catenin and $\alpha$-SMA indicates that the combined drugs have the potential to limit myofibroblasts generation. Moreover, BAY 41-2272 prevented the arrangement of $\alpha$ SMA in contractile fibrils, suggesting a reduced formation of contractile myofibroblasts. However, the combination of both drugs did not enhance this effect of BAY 41-2272. The above presented data showed that BAY 41-2272 and forskolin, are potent inhibitors of $\beta$-catenin and therefore may present novel therapeutic options for IPF. However, Wnt and $\beta$ catenin signalling are essential for the development and the function of the lung and its role in the pathogenesis of IPF has to be further studied [36].

The role of G-protein coupled receptors in the pathogenesis of fibrotic disease had been suggested in animal models earlier [37]. In a recent study, G-protein coupled receptors activity reduced fibroblast proliferation and differentiation by increasing cAMP [38]. However, the authors concluded that the level of cAMP generated by G-protein coupled receptors is not indicator of drug's efficacy and seems to follow a "yes" or "no" pattern. This observation was in part confirmed by the results displayed above, showing a sudden increase of inhibitory effects at concentrations $>10^{-8} \mathrm{M}$ for forskolin.

With regard to IPF therapy, nintedanib and pirfenidone achieved their beneficial effects in part by inhibiting TGF- $\beta 1$ $[39,40]$. However, both drugs have severe side effects and there is a need of alternative therapy options. One of such drug candidates is BAY 41-2272, which has been reported to prevent fibrosis in rat hearts [41]. The same drug had antiproliferative effects in vascular smooth muscle cells [42, 43]. BAY 41-2272 achieved its antiproliferative effects through the activation of CAMP and CGMP dependent protein kinases [43]. The data presented above show that BAY 41-2272 reduces fibroblasts proliferation in a concentration dependent manner, suggesting it may be a drug candidate for IPF treatment.

Fibrotic foci in IPF tissue are characterised by increased deposition of ECM, which is composed differently compared to ECM in the healthy lung $[9,13,26]$. The change in the composition of the ECM results from an increased deposition of collagens types I and III in the fibrotic foci and an overall increase of fibronectin. Nintedanib and Pirfenidone have the potential to reduce the accumulation of collagens and fibronectin in isolated cells; however, such an effect has not been proven in patient samples [7, 8, 39, 44]. The above presented data shows that sGC, such as BAY 412272 , may have a similar effect on reducing TGF- $\beta 1$ induced de novo deposition of collagen types I and III. However, neither BAY 41-2272 nor forskolin had a significant effect on TGF- $\beta 1$ induced fibronectin deposition, except at the highest concentration used in this study. Fibronectin has recently been indicated to play an essential role in wound repair and specifically in the recovery and function of epithelial cells [45]. Therefore, the lack of action of BAY 41-2272 on TGF- $\beta 1$ induced fibronectin deposition may be regarded as beneficial and restore the function of the epithelial cells in IPF.
The presented data indicates that sGC presents a novel class of drug for IPF therapy; however, this study was limited by the fact that the drugs were only investigated in nondiseased human lung fibroblasts and therefore no information was available if they achieve the same effect as diseased fibroblasts. We did not consider including animal models, since bleomycin-induced fibrosis does not represent the pathogenesis leading to IPF. Future studies are needed to clarify the beneficial effect of sGC on wound repair and tissue regeneration in IPF.

\section{Conclusions}

The data presented in this study indicates that BAY 41-2272, a sGC activator, may be considered as a novel therapeutic option for IPF. Furthermore, it may be beneficial to combine sGC activator with forskolin to improve their antifibrotic potential.

\section{Data Availability}

The data used to support the findings of this study are available from the corresponding author upon request.

\section{Conflicts of Interest}

The authors declare that they have no conflicts of interest.

\section{Acknowledgments}

We thank Mr. C.T. S'ng for correcting and editing the manuscript and the figures. This study was enabled by an unrestricted research grant from Bayer (Bayer Austria Ges.m.b.H.) to Ch. Lambers.

\section{References}

[1] A. L. Mora, M. Rojas, A. Pardo, and M. Selman, "Emerging therapies for idiopathic pulmonary fibrosis, a progressive agerelated disease," Nature Reviews Drug Discovery, vol. 16, no. 11, pp. 755-772, 2017.

[2] R. M. du Bois, "An earlier and more confident diagnosis of idiopathic pulmonary fibrosis," European Respiratory Review, vol. 21, no. 124, pp. 141-146, 2012.

[3] J. Hutchinson, A. Fogarty, R. Hubbard, and T. McKeever, "Global incidence and mortality of idiopathic pulmonary fibrosis: a systematic review," European Respiratory Society, vol. 46, no. 3, pp. 795-806, 2015.

[4] F. Ferri, Ferri's Clinical Advisor 2018 E-Book: 5 Books in 1, Elsevier Health Sciences, 2017.

[5] W. R. Coward, G. Saini, and G. Jenkins, "The pathogenesis of idiopathic pulmonary fibrosis," Therapeutic Advances in Respiratory Disease, vol. 4, no. 6, pp. 367-388, 2010.

[6] A. L. Tatler and G. Jenkins, "TGF-beta activation and lung fibrosis," Proceedings of the American Thoracic Society, vol. 9, no. 3, pp. 130-136, 2012.

[7] G. Epstein Shochet, L. Wollin, and D. Shitrit, "Fibroblast-matrix interplay: Nintedanib and pirfenidone modulate the effect of 
IPF fibroblast-conditioned matrix on normal fibroblast phenotype," Respirology, vol. 23, no. 8, pp. 756-763, 2018.

[8] L. Knuppel, Y. Ishikawa, M. Aichler et al., "A novel antifibrotic mechanism of nintedanib and pirfenidone inhibition of collagen fibril assembly," American Journal of Respiratory Cell and Molecular Biology, vol. 57, no. 1, pp. 77-90, 2017.

[9] M. Gabasa, P. Duch, I. Jorba et al., "Epithelial contribution to the profibrotic stiff microenvironment and myofibroblast population in lung fibrosis," Molecular Biology of the Cell (MBoC), vol. 28, no. 26, pp. 3741-3755, 2017.

[10] N. Khalil, T. V. Parekh, R. O'Connor et al., "Regulation of the effects of TGF- $\beta 1$ by activation of latent TGF- $\beta 1$ and differential expression of TGF- $\beta$ receptors (T $\beta$ R-I and T $\beta$ R-II) in idiopathic pulmonary fibrosis," Thorax, vol. 56, no. 12, pp. 907-915, 2001.

[11] H. Leufgen, M. P. Bihl, J. J. Rüdiger et al., "Collagenase expression and activity is modulated by the interaction of collagen types, hypoxia, and nutrition in human lung cells," Journal of Cellular Physiology, vol. 204, no. 1, pp. 146-154, 2005.

[12] Y. D. Xu, J. Hua, A. Mui, R. O'Connor, G. Grotendorst, and N. Khalil, "Release of biologically active TGF- $\beta 1$ by alveolar epithelial cells results in pulmonary fibrosis," American Journal of Physiology-Lung Cellular and Molecular Physiology, vol. 285, no. 3, pp. L527-L539, 2003.

[13] R. S. Nho and P. Hergert, "IPF fibroblasts are desensitized to type i collagen matrix-induced cell death by suppressing low autophagy via aberrant Akt/mTOR kinases," PLoS ONE, vol. 9, no. 4, Article ID e94616, 2014.

[14] I. P. Tomos, A. Tzouvelekis, V. Aidinis et al., "Extracellular matrix remodeling in idiopathic pulmonary fibrosis. It is the 'bed' that counts and not 'the sleepers,' Expert Review of Respiratory Medicine, vol. 11, no. 4, pp. 299-309, 2017.

[15] T. E. King Jr., W. Z. Bradford, S. Castro-Bernardini et al., "A phase 3 trial of pirfenidone in patients with idiopathic pulmonary fibrosis," The New England Journal of Medicine, vol. 370, no. 22, pp. 2083-2092, 2014.

[16] C. Beyer, N. Reich, S. C. Schindler et al., "Stimulation of soluble guanylate cyclase reduces experimental dermal fibrosis," Annals of the Rheumatic Diseases, vol. 71, no. 6, pp. 1019-1026, 2012.

[17] C. Beyer, C. Zenzmaier, K. Palumbo-Zerr et al., "Stimulation of the soluble guanylate cyclase (sGC) inhibits fibrosis by blocking non-canonical TGF $\beta$ signalling," Annals of the Rheumatic Diseases, vol. 74, no. 7, pp. 1408-1416, 2015.

[18] J.-P. Stasch, K. Dembowsky, E. Perzborn, E. Stahl, and M. Schramm, "Cardiovascular actions of a novel NO-independent guanylyl cyclase stimulator, BAY 41-8543: In vivo studies," British Journal of Pharmacology, vol. 135, no. 2, pp. 344-355, 2002.

[19] P. Deruelle, V. Balasubramaniam, A. M. Kunig, G. J. Seedorf, N. E. Markham, and S. H. Abman, "BAY 41-2272, a direct activator of soluble guanylate cyclase, reduces right ventricular hypertrophy and prevents pulmonary vascular remodeling during chronic hypoxia in neonatal rats," Biology of the Neonate, vol. 90, no. 2, pp. 135-144, 2006.

[20] B. Zhou, Y. Liu, M. Kahn et al., "Interactions between $\beta$ catenin and transforming growth factor- $\beta$ signaling pathways mediate epithelial- mesenchymal transition and are dependent on the transcriptional co-activator cAMP-response elementbinding protein (CREB)-binding protein (CBP)," The Journal of Biological Chemistry, vol. 287, no. 10, pp. 7026-7038, 2012.
[21] V. Della Latta, M. Cabiati, S. Rocchiccioli, S. Del Ry, and M.-A. Morales, "The role of the adenosinergic system in lung fibrosis," Pharmacological Research, vol. 76, pp. 182-189, 2013.

[22] C. Lambers, M. Roth, P. Jaksch et al., "Treprostinil inhibits proliferation and extracellular matrix deposition by fibroblasts through cAMP activation," Scientific Reports, vol. 8, no. 1, article no. 1087, 2018.

[23] C. Lambers, L. Costa, Q. Ying et al., "Aclidinium bromide combined with formoterol inhibits remodeling parameters in lung epithelial cells through cAMP," Pharmacological Research, vol. 102, pp. 310-318, 2015.

[24] C. Lambers, Y. Qi, P. Eleni et al., "Extracellular matrix composition is modified by $\beta 2$-agonists through cAMP in COPD," Biochemical Pharmacology, vol. 91, no. 3, pp. 400-408, 2014.

[25] G. Raghu, H. R. Collard, J. J. Egan et al., "An Official ATS/ERS/ JRS/ALAT statement: idiopathic pulmonary fibrosis: evidencebased guidelines for diagnosis and management," American Journal of Respiratory and Critical Care Medicine, vol. 183, no. 6, pp. 788-824, 2011.

[26] N. J. Lomas, K. L. Watts, K. M. Akram, N. R. Forsyth, and M. A. Spiteri, "Idiopathic pulmonary fibrosis: Immunohistochemical analysis provides fresh insights into lung tissue remodelling with implications for novel prognostic markers," International Journal of Clinical and Experimental Pathology, vol. 5, no. 1, pp. 58-71, 2012.

[27] A. Joannes, S. Brayer, V. Besnard et al., "FGF9 and FGF18 in idiopathic pulmonary fibrosis promote survival and migration and inhibit myofibroblast differentiation of human lung fibroblasts in vitro," American Journal of Physiology-Lung Cellular and Molecular Physiology, vol. 310, no. 7, pp. L615-L629, 2016.

[28] D. Pattarayan, A. Sivanantham, V. Krishnaswami et al., "Tannic acid attenuates TGF- $\beta$ 1-induced epithelial-to-mesenchymal transition by effectively intervening TGF- $\beta$ signaling in lung epithelial cells," Journal of Cellular Physiology, vol. 233, no. 3, pp. 2513-2525, 2018.

[29] T. Wang, Y. Liu, J. Zou, Z. Cheng, and A. Ahmad, "Interleukin17 induces human alveolar epithelial to mesenchymal cell transition via the TGF- $\beta 1$ mediated Smad $2 / 3$ and ERK1/2 activation," PLoS ONE, vol. 12, no. 9, p. e0183972, 2017.

[30] H. Chen, Q. Chen, C.-M. Jiang et al., "Triptolide suppresses paraquat induced idiopathic pulmonary fibrosis by inhibiting TGFB1-dependent epithelial mesenchymal transition," Toxicology Letters, vol. 284, pp. 1-9, 2018.

[31] J. Shi, F. Li, M. Luo, J. Wei, and X. Liu, "Distinct roles of Wnt/ $\beta$-catenin signaling in the pathogenesis of chronic obstructive pulmonary disease and idiopathic pulmonary fibrosis," Mediators of Inflammation, vol. 2017, Article ID 3520581, 16 pages, 2017.

[32] P. Song, J.-X. Zheng, J.-Z. Liu et al., "Effect of the Wnt1/ $\beta$ catenin signalling pathway on human embryonic pulmonary fibroblasts," Molecular Medicine Reports, vol. 10, no. 2, pp. 10301036, 2014.

[33] L. Xu, W.-H. Cui, W.-C. Zhou et al., "Activation of Wnt/ $\beta$ catenin signalling is required for $\mathrm{TGF}-\beta / \mathrm{Smad} 2 / 3$ signalling during myofibroblast proliferation," Journal of Cellular and Molecular Medicine, vol. 21, no. 8, pp. 1545-1554, 2017.

[34] P. Song, J.-X. Zheng, J. Xu, J.-Z. Liu, L.-Y. Wu, and C. Liu, “ $\beta$ catenin induces A549 alveolar epithelial cell mesenchymal transition during pulmonary fibrosis," Molecular Medicine Reports, vol. 11, no. 4, pp. 2703-2710, 2015.

[35] Z. Sun, X. Gong, H. Zhu et al., "Inhibition of Wnt/ $\beta$-catenin signaling promotes engraftment of mesenchymal stem cells to 
repair lung injury," Journal of Cellular Physiology, vol. 229, no. 2, pp. 213-224, 2014.

[36] W. Skronska-Wasek, R. Gosens, M. Königshoff, and H. A. Baarsma, "WNT receptor signalling in lung physiology and pathology," Pharmacology \& Therapeutics, vol. 187, pp. 150-166, 2018.

[37] Y. Shimizu, K. Dobashi, K. Iizuka et al., "Contribution of small GTPase Rho and its target protein ROCK in a murine model of lung fibrosis," American Journal of Respiratory and Critical Care Medicine, vol. 163, no. 1, pp. 210-217, 2001.

[38] M. J. Roberts, R. E. Broome, T. C. Kent, S. J. Charlton, and E. M. Rosethorne, "The inhibition of human lung fibroblast proliferation and differentiation by Gs-coupled receptors is not predicted by the magnitude of cAMP response," Respiratory Research, vol. 19, no. 1, article no. 2771, 2018.

[39] S. Rangarajan, A. Kurundkar, D. Kurundkar et al., "Novel mechanisms for the antifibrotic action of nintedanib," American Journal of Respiratory Cell and Molecular Biology, vol. 54, no. 1, pp. 51-59, 2016.

[40] E. Conte, E. Gili, E. Fagone, M. Fruciano, M. Iemmolo, and C. Vancheri, "Effect of pirfenidone on proliferation, TGF-betainduced myofibroblast differentiation and fibrogenic activity of primary human lung fibroblasts," European Journal of Pharmaceutical Sciences, vol. 58, no. 1, pp. 13-19, 2014.

[41] H. Masuyama, T. Tsuruda, Y. Sekita et al., "Pressureindependent effects of pharmacological stimulation of soluble guanylate cyclase on fibrosis in pressure-overloaded rat heart," Hypertension Research, vol. 32, no. 7, pp. 597-603, 2009.

[42] N. N. Mendelev, V. S. Williams, and D. A. Tulis, "Antigrowth properties of BAY 41-2272 in vascular smooth muscle cells," Journal of Cardiovascular Pharmacology, vol. 53, no. 2, pp. 121131, 2009.

[43] C. N. Joshi, D. N. Martin, J. C. Fox, N. N. Mendelev, T. A. Brown, and D. A. Tulis, "The soluble guanylate cyclase stimulator BAY 41-2272 inhibits vascular smooth muscle growth through the cAMP-dependent protein kinase and cGMP-dependent protein kinase pathways," The Journal of Pharmacology and Experimental Therapeutics, vol. 339, no. 2, pp. 394-402, 2011.

[44] M. Molina-Molina, C. Machahua-Huamani, V. VicensZygmunt et al., "Anti-fibrotic effects of pirfenidone and rapamycin in primary IPF fibroblasts and human alveolar epithelial cells," BMC Pulmonary Medicine, vol. 18, no. 1, p. 63, 2018.

[45] E. A. Lenselink, "Role of fibronectin in normal wound healing," International Wound Journal, vol. 12, no. 3, pp. 313-316, 2015. 


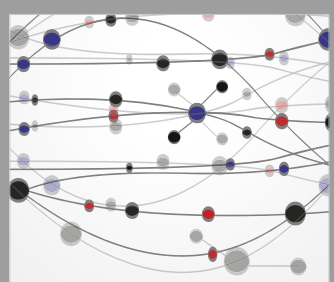

The Scientific World Journal
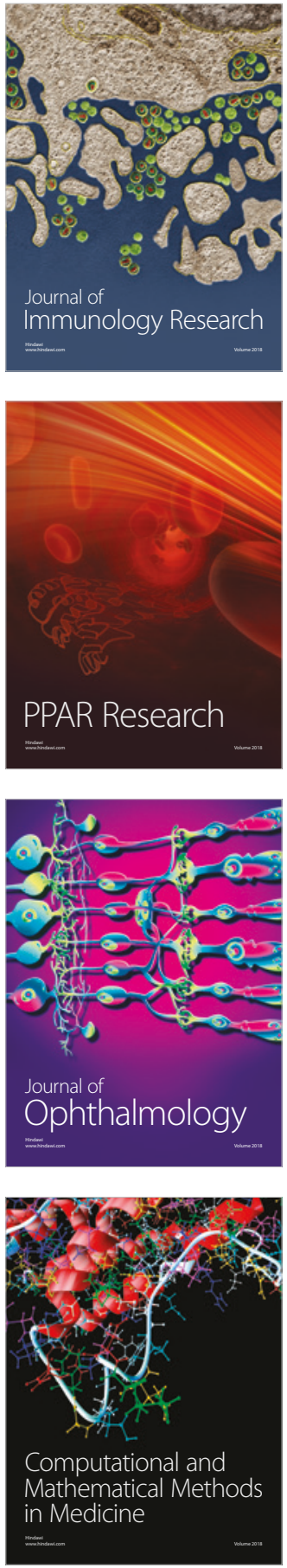

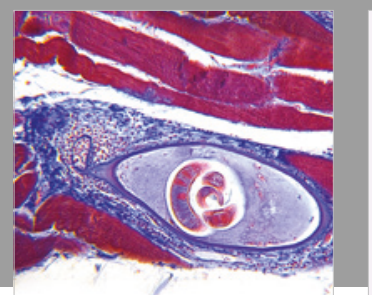

Gastroenterology Research and Practice

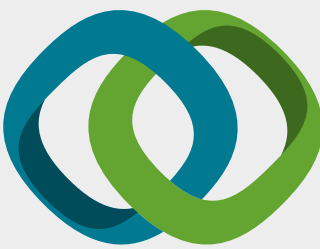

\section{Hindawi}

Submit your manuscripts at

www.hindawi.com
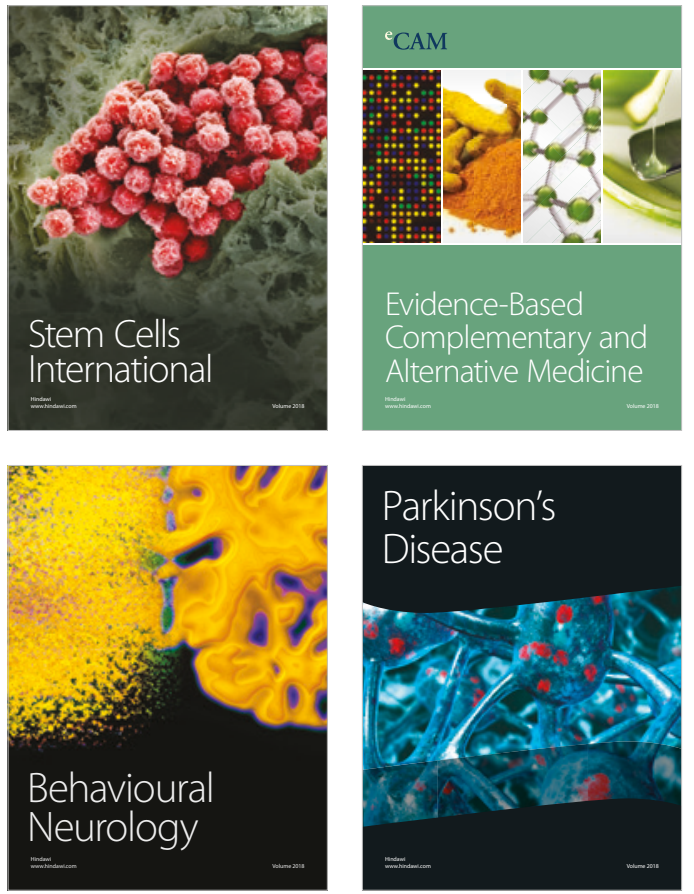

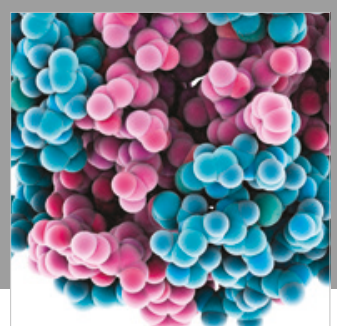

ournal of

Diabetes Research

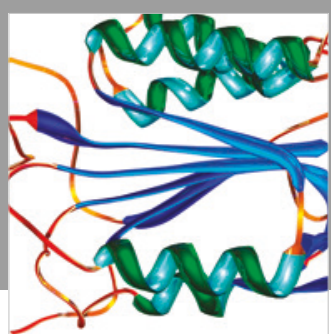

Disease Markers
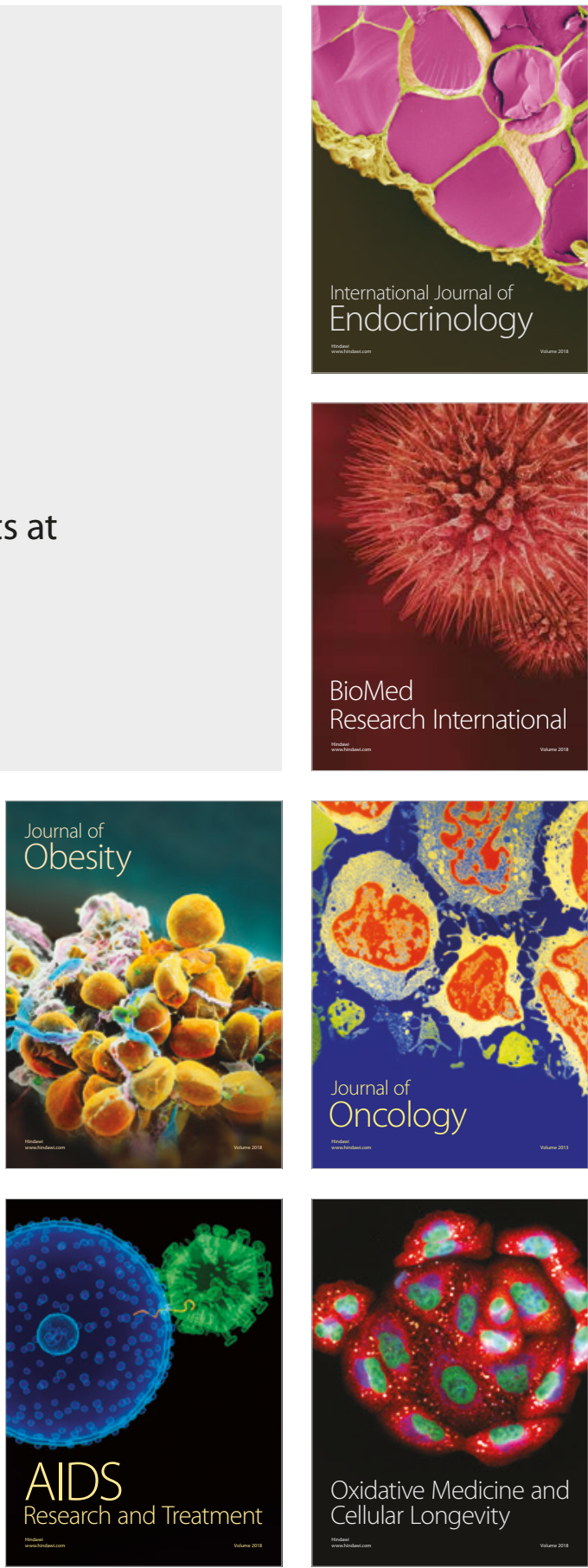